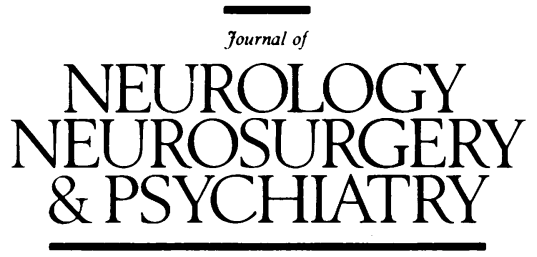

Editorial

\title{
PET: its clinical role in neurology
}

Positron emission tomography (PET) provides a noninvasive means of measuring the metabolism, perfusion, and pharmacology of human organs in vivo. A tracer tagged with a short-lived positron emitting isotope, such as ${ }^{15} \mathrm{O},{ }^{11} \mathrm{C}$, or ${ }^{18} \mathrm{~F}$ (half-lives 2,20 , and 110 minutes respectively), is generated by a cyclotron and radministered intravenously, or by inhalation to the subject. Quantitative tomographic images of regional cerebral function can be generated using established mathematical models from the scans of regional cerebral tracer uptake with a knowledge of the arterial plasma tracer activity. Examples of tracers in common usage to measure blood flow are $\mathrm{C}^{15} \mathrm{O}_{2}, \mathrm{H}_{2}{ }^{15} \mathrm{O}$, and ${ }^{18} \mathrm{FCH}_{3}$, while oxygen and glucose utilisation can be assessed with ${ }^{15} \mathrm{O}_{2}$ and ${ }^{18} \mathrm{~F}-2$ fluoro-2-deoxyglucose (FDG) respectively.

Levels of striatal ${ }^{18} \mathrm{~F}$-6-fluorodopa and ${ }^{11} \mathrm{C}$-nomifensine uptake provide a measure of functional integrity of the nigro-striatal dopaminergic system, while dopamine $D_{1}$, and $\mathrm{D}_{2}$, serotonin $5 \mathrm{HT}_{2}$, opiate, and benzodiazepine receptor densities can be estimated using tracers such as ${ }^{11} \mathrm{C}-\mathrm{SCH}$ 23390, ${ }^{11} \mathrm{C}$-Raclopride, ${ }^{18} \mathrm{~F}$-Setoperone, ${ }^{11} \mathrm{C}$ Carfentanil and ${ }^{11} \mathrm{C}$-Diprenorphine, and ${ }^{11} \mathrm{C}$-Flumazenil respectively. PET has been criticised as being highly expensive, relatively unavailable, and that it has contributed little to the clinical practice of neurology. The first two criticisms are becoming less valid as "Clinical PET" centres begin to spring up, and indeed there is now an Institute of Clinical PET in the USA. As for the third criticism it is perhaps worth remembering that PET was never originally envisaged as a clinical tool. Despite this, a number of interesting roles for PET in the practice of clinical neurology have emerged which this editorial will discuss.

\section{a) The dementias}

It is now established that the majority of patients with Alzheimer's disease show a characteristic pattern of reduced cortical metabolism and blood flow which is most severe in posterior parietal and temporal lobes, with relative sparing of the sensorimotor and occipital cortices. $^{1-4}$ These changes on functional imaging may be present before any atrophic changes are evident on CT or MRI. More interestingly, if patients complaining of recent onset of poor short term recall are scanned, there is a high correlation between the presence of posterior parietal and temporal hypofunction on PET and the subsequent development of frank dementia of Alzheimer type (DAT).$^{5}$ Functional imaging can therefore provide a means of distinguishing memory impairment due to early DAT from that due to other causes such as the pseudo- dementia associated with depression. In depression, like DAT, a general reduction in cortical blood flow and metabolism occurs, but pre-frontal rather than parietal and temporal cortex is most severely involved, and the prefrontal hypofunction may reverse on successful treatment of the affective disorder. ${ }^{6}$

At its onset dementia due to frontal lobar degeneration may be clinically difficult to differentiate from $\mathrm{Alz}$ heimer's disease as loss of short-term recall and change of personality are frequent presenting features of both conditions. Subjects with Pick's disease show generalised cortical hypometabolism on functional imaging, but in contrast to Alzheimer's disease the prefrontal rather than the posterior parietal and temporal regions are most severely affected. ${ }^{7-9}$ Prefrontal hypofunction is not specific for Pick's disease, but can also be found in dementia of frontal type (DFT) due to spongiform degeneration, ${ }^{10}$ and in the so called "sub-cortical dementias" due to conditions such as progressive supranuclear palsy (PSP) ${ }^{11-13}$ and Huntington's disease. ${ }^{14}$ While cortical glucose metabolism is most severely reduced in frontal regions in PSP, it has suggested that it is the premotor and supplementary motor areas rather than the prefrontal areas that are targeted,,$^{15}$ distinguishing this condition from Pick's disease. Demented patients with Parkinson's disease generally show a DAT rather than DFT pattern of cortical hypofunction. ${ }^{14}$ There have not been enough pathological studies yet to determine whether the low posterior parietal and temporal metabolism seen in demented PD patients simply represents coexistent Alzheimer's disease, or whether it can also result from cortical Lewy body disease or loss of cortical cholinergic, noradrenergic, and serotonergic afferents.

It can be seen therefore that PET can help to distinguish the cortical and subcortical dementias in their early clinical phases by delineating patterns of altered regional cerebral blood flow and metabolism, and so aid in counselling patients and their relatives, and in classifying dementia patients for entry into therapeutic trials. PET can also differentiate the degenerative dementias from other dementing illnesses such as multi-infarct disease where randomly distributed focal deficits in cortical and subcortical metabolism are found ${ }^{1617}$ and from normal pressure hydrocephalus where cortical function is uniformly depressed. ${ }^{18} 19$ It will be necessary to perform prospective clinical trials, however, to fully evaluate the sensitivity and specificity of functional imaging in the differential diagnosis of the dementias.

An interesting sub-group is the focal cortical degenerations leading to progressive aphasia, apraxia, agnosia and 
cortical blindness. The pathologies of these conditions are not unique: focal Alzheimer, Pick's and spongiform changes have all been reported. ${ }^{20-22}$ These patients frequently have normal structural imaging at the disease onset, and have on occasion been thought hysterical. Functional imaging provides a sensitive means of demonstrating the presence and extent of the focal cortical hypometabolism present in these patients, and may show changes when structural imaging is unhelpful..$^{23}$ A recently recognised entity is corticobasal degeneration, also known as corticodentatonigral degeneration and neuronal achromasia. This condition presents as an asymmetric, non-levodopa responsive, akinetic-rigid syndrome with apraxia or cortical sensory loss in affected limbs. ${ }^{24}$ An alien-limb (a limb that performs involuntary apparently purposeful movements), supranuclear gaze palsy, pseudobulbar palsy, and myoclonus may also be present. The pathology consists of asymmetrical focal collections of swollen achromatic neurons in the posterior frontal, inferior parietal, and superior temporal cortices, substantia nigra, and dentate nuclei. PET reveals a characteristic pattern of hypometabolism involving these cortical areas even when structural imaging is normal, and so can aid in diagnosing this fascinating condition. ${ }^{25}$

PET can also be used to demonstrate the functional effects of pathology that remain occult to conventional clinical assessment. Hatazawa et $a l^{26}$ measured regional cerebral glucose metabolism in 12 patients with motor neuron disease (MND). Eight of their MND cases had both lower and upper motor neuron involvement and all showed widespread cortical and sub-cortical hyopfunction, the sensorimotor cortex being most severely affected. Four MND patients with only lower motor neuron involvement showed no abnormalities of cerebral function. The widespread cerebral hypofunction in the group of eight patients with upper motor neuron disease is probably caused by diffuse loss of Betz cells from the cortex and disconnection of structures from the primary motor cortex and pyramidal tracts. Functional imaging should potentially provide a sensitive means of determining whether upper motor neuron involvement is present in those MND patients where this is in doubt. PET studies have also shown that multiple sclerosis patients develop severe generalised cortical hypometabolism in association with their white matter disease, and that this is too extensive to be simply a consequence of cortical disconnection by the discrete white matter plaques present. ${ }^{27}{ }^{28}$ It would appear that apparently structurally normal brain tissue functions abnormally in MS patients, explaining the high incidence of cognitive dysfunction in this condition.

\section{b) Cerebrovascular disease}

PET can be used to study the widespread metabolic derangements caused by discrete ischaemic lesions, to study the adaptive mechanisms the brain brings into play to effect a functional recovery from strokes, and to study the haemodynamic changes associated with the pre-ischaemic, and ischaemic state. As a lacunar infarct may cause extensive functional disconnection, PET is a more sensitive means of detecting ischaemic lesions than CT or MRI. The size of metabolic deficits, and the level of their glucose utilisation, has been shown to correlate with the eventual clinical outcome of stroke patients. ${ }^{29}$

Ninety per cent of motor cortex pyramidal fibres project to the contralateral limbs, but a functional ipsilateral pathway exists as shown by the mild proximal weakness of ipsilateral limbs experienced by patients after stroke involving the motor cortex. ${ }^{30}$ If patients who have made an apparent complete clinical recovery from a hemiparesis are studied with PET, abnormalities of cerebral activation can be detected. Normally when the fingers of one hand are touched in turn with the thumb there is a significant increase in blood flow in the contralateral sensorimotor cortex, bilateral supplementary motor and premotor areas, and ipsilateral cerebellar hemisphere. Some patients who have recovered from hemipareses show abnormal ipsilateral sensorimotor cortex and contralateral cerebellar hemisphere activation when the affected hand is used, suggesting that activation of ipsilateral motor pathways plays a role in their functional recovery. ${ }^{31}$ Similarly, patients who are recovering from expressive dysphasia due to dominant hemisphere stroke may show abnormal activation of the non-dominant hemisphere if asked to generate words. ${ }^{32}$

When a carotid artery becomes more than $70 \%$ stenosed, and cerebral perfusion pressure falls, two adaptive mechanisms come into play. Firstly the brain attempts to maintain blood flow by reducing vascular resistance. The result is dilatation of the distal microvasculature with an increase in cerebral blood volume in the territory supplied by that carotid artery. ${ }^{33} 34$ Secondly, as vasodilatation becomes maximal and blood flow falls, the brain maintains oxygen metabolism by increasing the fraction of oxygen extracted from the arterial supply from a normal $40 \%$ level towards a maximal $100 \%$, at which point a state of ischaemia is reached. Any further fall in perfusion pressure will result in infarction. Acute stroke is associated with raised levels of arterial oxygen extraction, low blood flow, and acid tissue $\mathrm{pH}$. As infarction is completed the cerebral oxygen extraction and metabolism fall to low levels. Reperfusion may occur within the next few hours leading to a rise in blood flow and conversion of tissue $\mathrm{pH}$ from acid to alkaline. As tissue metabolism remains low, however, restoration of cerebral perfusion results in a state of luxury perfusion. ${ }^{35-37}$

All the above regional cerebral haemodynamic and metabolic changes can be monitored with PET, and patients with impaired haemodynamic and oxygen reserves due to stenosed or occluded extra-cranial arteries can be identified. It is now well established that revascularisation surgery can reverse the haemodynamic effects of carotid stenosis. ${ }^{38-41}$ Only small numbers of patients have been studied to date, however, and reported clinical follow up is limited to two years. Data from a single uncontrolled, nonblinded study are discouraging, failing to show any marked improvement in prognosis of patients with dilated microvasculature who had revascularisation compared with those who were treated conservatively. ${ }^{42}$ Controlled trials are needed to resolve this question.

PET has shown that many infarcts spontaneously reperfuse within hours of the onset. Consequently the use of therapy designed to increase cerebral perfusion from this time onwards, such as haemodilution and calcium channel antagonists, is inappropriate. If attempts are going to be made to revascularise ischaemic brain then PET findings suggest that this must be done within those first hours while oxygen extraction remains high. With the advent of cerebral protective agents, such as glutamate antagonists and free radical scavengers, a valuable future role for PET is likely to lie in the evaluation of the efficacy of these drugs in restoring cerebral metabolism after infarction.

\section{c) Movement disorders}

PET çan provide a valuable adjunct to clinical assessment in helping to distinguish the various akinetic-rigid syndromes, and is able to detect sub-clinical involvement in atrisk subjects. The patterns of cortical metabolic disturbance associated with akinetic rigid syndromes have already been discussed in section a. Striatal metabolism is 
normal in Parkinson's disease (PD), ${ }^{14} 43$ while conditions associated with striatal degeneration such as multiple system atrophy (MSA) and progressive supranuclear palsy (PSP), show significant falls in striatal glucose utilisation. ${ }^{11-131544}$ Huntington's disease results in severe degeneration of the caudate nuclei, and affected patients may show low caudate glucose metabolism before any atrophic changes are evident on CT ${ }^{45}$ Unfortunately, the finding of selective caudate hypometabolism is not specific for HD, having also been reported in chorea associated with benign familial chorea, neuroacanthocytosis, and dentatopallidorubroluysian atrophy. ${ }^{46}$ Subjects at risk for Huntington's disease have been studied with PET, and a high concordance between the presence of caudate hypometabolism and DNA linkage abnormalities has been reported. ${ }^{47}$ It is unlikely that functional imaging will replace DNA studies as a means of diagnosing $\mathrm{HD}$, but where inadequate genetic material is available it may prove useful in supporting or refuting the diagnosis.

The pre- and post-synaptic dopaminergic system has been extensively studied with PET in patients with movement disorders. In sporadic levodopa responsive PD there is a characteristic pattern of striatal ${ }^{18} \mathrm{~F}$-Dopa uptake, putamen tracer uptake being on average reduced to $40 \%$, and caudate $80 \%$, of normal. ${ }^{48}$ Striatal ${ }^{18}$ F-Dopa uptake reflects functional integrity of the nigro-striatal dopaminergic projections, and these PET findings fit in with the pathological observation that nigra compacta cell counts are reduced to $15-30 \%$ of normal in $\mathrm{PD}$, the ventro-lateral projections to the putamen being most severely affected. Levels of putamen ${ }^{18} \mathrm{~F}$-Dopa uptake correlate with locomotor function of PD patients, and on-off fluctuators have lower levels of tracer uptake than patients with a sustained response to therapy. ${ }^{49}$ PSP patients also show a severe fall in putamen ${ }^{18} \mathrm{~F}$-Dopa uptake, but in contrast to PD the caudate tracer uptake in PSP is as severely affected as putamen. ${ }^{48}$ Again these PET observations fit with the pathological finding of a uniform nigral involvement in PSP.

${ }^{18}$ F-Dopa PET can be used to detect presymptomatic nigral involvement in subjects. Abnormal striatal ${ }^{18} \mathrm{~F}$-Dopa uptake has been demonstrated in asymptomatic subjects exposed to MPTP, ${ }^{50}$ and occasionally in patients made rigid with conventional doses of dopamine receptor blocking agents used as vestibular sedatives or neuroleptics. ${ }^{51}$ Work is currently under way scanning twins and relatives of Parkinson's disease patients with ${ }^{18} \mathrm{~F}$-Dopa to try and determine the role of inheritance in this condition. Preliminary data suggest that the concordance for nigral pathology in PD twin pairs may be higher than was previously thought. Patients with isolated tremor are also having ${ }^{18} \mathrm{~F}$-Dopa PET to clarify the relationship between essential tremor (ET) and nigral pathology. Our data currently suggest that patients with a predominantly postural tremor and a verifiable family history of ET have normal levels of striatal ${ }^{18} \mathrm{~F}$-Dopa uptake (Brooks DJ, unpublished observations).

The beneficial effects of dopamine agonists in PD are mediated through dopamine $\mathrm{D}_{2}$ receptors. There has been confusion in the pathological literature over the status of striatal dopamine $\mathrm{D}_{2}$ receptors in Parkinson's disease, up and down regulation, and normal levels have all been reported. Using the $\mathrm{D}_{2}$ antagonist ${ }^{11} \mathrm{C}$-Raclopride, two PET studies have now shown that in untreated PD there is relative upregulation of putamen $\mathrm{D}_{2}$ binding sites contralateral to the more affected limbs. ${ }^{52}{ }^{53}$ Absolute levels of striatal $\mathrm{D}_{2}$ binding sites in untreated PD fall within the normal range, while in chronically treated PD subjects, who have developed a fluctuating response to levodopa, caudate and putamen $\mathrm{D}_{2}$ binding sites are uniformly reduced. $^{51}$ Poor levodopa responsive MSA and PSP patients show similar reductions in striatal $\mathrm{D}_{2}$ binding site density to on-off PD fluctuators, ${ }^{51}$ though putamen is targeted in MSA and caudate in PSP. This suggests that the lack of levodopa response in MSA and PSP is not due to loss of striatal $\mathrm{D}_{2}$ sites alone, but is caused by loss of other basal ganglia and brain stem connections.

PET has also been used to study the cerebellar ataxias. In sporadic and familial olivopontocerebellar atrophy (OPCA) cerebellar and brain-stem glucose hypometabolism are found before CT or MRI abnormalities are seen. ${ }^{55}$ PET can also be used to demonstrate cerebellar involvement in patients with multiple system atrophy. ${ }^{4456}$ Interestingly, in contrast to other causes of cerebellar degeneration, patients with early Friedreich's ataxia show elevated rather than reduced cerebellar glucose metabolism, though this later falls as the disease becomes more advanced. ${ }^{57}$

In summary, it can be seen that PET can be used to help distinguish the various degenerative causes of akineticrigid syndromes by revealing their different patterns of cortical, striatal, and cerebellar metabolic dysfunction, and their different patterns of disruption of the pre- and postsynaptic striatal dopaminergic systems. These changes on functional imaging are often seen in the absence of abnormalities on CT or MRI. PET can also be used to detect the presence of underlying nigral pathology in patients with isolated tremors or drug-associated rigidity, and striatal hypofunction in subjects at risk for Huntington's disease.

\section{d) Epilepsy}

The majority of functional imaging studies have been performed on patients with focal epilepsy. A problem with the use of PET for studying the regional cerebral metabolic or blood flow changes associated with seizures is that PET tracers have short half-lives. As a consequence unless a patient has a spontaneous or induced fit during scanning, most PET studies are of necessity interictal. The most widely used PET metabolic tracer has been ${ }^{18} \mathrm{FDG}$, whose cerebral uptake reflects glucose metabolism. This tracer is poorly extracted by the brain and so tracer uptake must be followed for 45 minutes. If a subject has a seizure during an FDG scan, the effect of the seizure on tracer uptake is dependent on the proximity of the fit to the time of tracer injection.

Despite these methodological problems a considerable amount of PET FDG data on epileptic subjects has been gathered. Generalised seizures appear to cause a diffuse increase in cerebral glucose utilisation, but the FDG approach does not have the temporal resolution to determine the site of initiation of ictal activity. ${ }^{58}$ Sixty to eighty per cent of patients with lateralised foci on surface and depth EEG show ipsilateral glucose hypometabolism interictally, the area of low FDG uptake being far more extensive than that of the EEG focus. ${ }^{59-61}$ Those patients with partial focal seizures that have had ictal scans show glucose hypermetabolism in the same area as the interictal glucose hypometabolism, though changes may be more widespread due to the spread of seizure activity. Seizure lateralisation determined by ictal PET studies has a $90 \%$ concordance with that determined by surface and depth EEG. Pathological studies on resected temporal lobe found lesions with a $60-80 \%$ concordance with PET lateralisation of seizure foci. ${ }^{62} \mathrm{PET}$ is most frequently abnormal in cases of mesial temporal sclerosis, but will also detect neoplasms, vascular malformations, and heterotopias responsible for focal seizures.

Initial series suggested that MRI was a far less effective technique for detecting abnormalities in focal epilepsy than functional imaging, picking up lesions in only $40 \%$ of 
cases. ${ }^{63}$ With the advent of new scanning sequences, and cuts orientated along the axis of the temporal lobes, MRI is now more sensitive at detecting mesial temporal sclerosis and may be becoming as effective as PET in lateralising focal abnormalities. While functional imaging provides an excellent means of lateralising focal seizures, the metabolic disturbance revealed is often widespread and so PET may not reliably differentiate frontal from temporal lobe foci. In spite of this drawback, several neurosurgical centres now feel that depth electrode EEG studies are no longer necessary to lateralise the focus in patients with a good history for focal epilepsy, but a normal surface EEG, if regional hypofunction can be demonstrated with interictal functional imaging.

\section{e) Conclusions}

PET can demonstrate characteristic patterns of disruption of regional cerebral hypometabolism and neurotransmitter systems associated with the cortical and sub-cortical degenerations, and so help to characterise the type of dementia or akinetic-rigid syndrome affecting patients when this remains unclear after clinical assessment and structural imaging. Sub-clinical involvement in subjects at-risk for degenerative conditions such as Alzheimer's, Parkinson's, and Huntington's diseases can also be demonstrated. In cases where extracranial artery stenosis is causing impaired cerebral perfusion, PET can assess the degree of haemodynamic compromise present, and provide a rationale for revascularisation. Functional imaging is valuable for lateralising epileptic foci in patients with focal seizures who have a normal surface EEG and are under consideration for temporal lobectomy, enabling avoidance of the use of depth electrode studies in certain instances. Finally PET can give insight into the adaptive mechanisms the brain uses to overcome focal injury, and can directly monitor the effects of therapy on regional cerebral metabolism.

Some of the applications of PET described in this editorial can also be studied with the cheaper and more widely available technique of single photon emission computerised tomography (SPECT). Using ${ }^{99 \mathrm{~m}} \mathrm{Tc}$ tracers such as HMPAO, SPECT provides qualitative measurements of regional cerebral blood flow, and tracers are now available for studying $\mathrm{D}_{2}$, cholinergic, and benzodiazepine receptors. Using SPECT Alzheimer's disease can be distinguished from DFT, the functional effects of focal degenerative disease and infarction can be detected, and the flow changes associated with focal epilepsy can be lateralised. It is not the purpose of this editorial to compare PET and SPECT, but rather to illustrate their clinical role in neurology. Currently PET is the more versatile and sensitive of the two techniques, but as the designers of SPECT tracers become more ingenious the gap between PET and SPECT is likely to close.

\section{DAVID J BROOKS}

MRC Cyclotron Unit

Hammersmith Hospital, London.

1 Frackowiak RSJ, Pozilli C, Legg NJ, et al. Regional cerebral oxygen supply and in dementia A clinical and physiological study with 15 and positron emission tomography. Brain 1981;104:753-78.

2 Benson DF, Kuhl DE, Hawkins RA, et al. The fluorodeoxyglucose ${ }^{18} \mathrm{~F}$ scan in Alzheimer's disease and multi-infarct dementia. Arch Neurol 1983;40:711-14

3 Duara R, Grady C, Haxby J, et al. Positron emission tomography in Alzheimer's disease. Neurology 1986;36:879-87.

4 Herholz K, Adams $\mathrm{R}$, Kessler J, et al. Criteria for the diagnosis of Alzheimer's disease with positron emission tomography. Dementia (in press).

5 Kuhl DE, Small GW, Riege WH, et al. Cerebral metabolic patterns before the diagnosis of probable Alzheimer's disease. J Cereb Blood Flow Metabol 1987;7:S406.

6 Baxter LR; Schwartz JM, Phelps ME, et al. Reduction of prefrontal cortex glucose metabolism common to three types of depression. Arch Gen Psychiat 1989;46:243-50.

7 Kamo H, McGeer P, Harrop R. PET and histopathology in Pick's disease.
Neurology 1987;37:439-45.

Salmon E, Maquet P, Sadzot B, et al. Positron emission tomography in Alzheimer's and Pick's disease. J Neurol 1988;235:S1.

9 Brion S, Mikol J, Baron JC, et al. Neuroimaging in Pick's disease with histological data. $J$ Neurol 1988;235:S1.

10 Neary D, Snowden JS, Northen B. Dementia of frontal lobe type. J Neurol Neurosurg Psychiatry 1988;51:353-61.

11 Blin J, Baron JC, Dubois B, et al. Positron emission tomography in progressive supranuclear palsy. Brain hypometabolic pattern and clinicometabolic correlations. Arch Neurol 1990;47:747-52.

12 Foster NL, Gilman S, Berent S, Morin EM, Broen MB, Koeppe RA. Cerebral hypometabolism in progressive supranuclear palsy studied with positron emission tomography. Ann Neurol 1988;24:399-406.

13 Leenders KL, Frackowiak RSJ, Lees AJ. Steele-Richardson-Olszewski syndrome. Brain energy metabolism, blood flow, and fluorodopa uptake syndrome. Brain energy metabolism, blood fow, and fluorodopa uptake

14 Kuhl DE, Metter EG, Riege WH, Markham CH. Patterns of cerebral glucose utilisation in Parkinson's disease and Huntington's disease. Ann Neurol 1984;15:S119-S125.

15 Goffinet AM, De Volder AG, Gillain C, et al. Positron emission tomography demonstrates frontal lobe hypometabolism in progressive supranuclear palsy. Ann Neurol 1989;25:131-9.

16 Benson DF, Kuhl DE, Hawkins RA, et al. The fluorodeoxyglucose ${ }^{18} \mathrm{~F}$ scan in Alzheimer's disease and multi infarct dementia. Arch Neurol 1983;40:711-14.

17 Pawlik G, Holthoff V, Rudolf J, Bönner J, Heiss WD. Vasculitic dementia: Characteristic changes of regional brain function demonstrated by PET. $J$ Cereb Blood Flow Metabol 1989;9:S534.

12 Jagust WJ, Friedland RP, Budinger TF. Positron emission tomography with $\left.{ }^{11} \mathrm{~F}\right)$ fluorodeoxyglucose differentiates normal pressure hydrocephalus from Alzheimer type dementia. J Neurol Neurosurg Psychiatry 1985;48:1091-6.

19 Brooks DJ, Beaney RP, Powell M, et al. Studies on cerebral oxygen metabolism, blood flow, and blood volume in patients with hydrocephalus before and after surgical decompression, using positron emission tomography. Brain 1986;109:613-28.

20 Pogacar S, Williams RS. Alzheimer's Disease presenting as slowly progressive aphasia. Rhode Island Med J 1984;67:181-5.

21 Wechsler AF, Verity A, Rosenschein S, Fried I, Scheibel AB. Pick's Disease A clinical, computed tomographic, and histologic study with Golgi impregnation observations. Arch Neurol 1982;39:287-90.

22 Kirshner HS, Tanridag O, Thurman L, Whetsell WO. Progressive aphasia without dementia: Two cases with focal spongiform degeneration. Ann Neurol 1987;22:527-32.

23 Tyrell P, Warrington E, Frackowiak RSJ, Rossor M. Heterogeneity in slowly progressive aphasia due to focal cortical atrophy: a clinical and PET scan study. Brain 1990;113:1321-36.

24 Gibb WR, Luthert $P$ Marsden CD Corticobasal Degeneration. Brain 1989;112:1171-92.

25 Sawle GC, Brooks DJ, Marsden CD, Frackowiak RSJ. Corticobasal Degeneration: $A$ unique pattern of regional cortical oxygen metabolism and striatal fluorodopa uptake demonstrated by positron emission tomography. Brain (in press)

26 Hatazawa J, Brooks RA, Dalakas MC, Mansi L, Di Chiro G. Cortical MotorSensory Hypometabolism in Amyotrophic Lateral Sclerosis: A PET study. J Comp Assist Tomogr 1988;12:630-6.

27 Brooks DJ, Leenders KL, Head G, et al. Studies on regional cerebral oxygen utilisation and cognitive function in Multiple Sclerosis. $J$ Neurol Neurosurg Psychiatry 1984;47:1182-91.

28 Perani D, Fieschi C, Comi GC, et al. PET in multiple sclerosis: clinical/ metabolic correlation study. Neurology 1990;40(Suppl):264.

29 Kushner M, Reivich M, Fieschi C, et al. Metabolic and clinical correlates of acute ischemic infarction. Neurology 1987;37:1103-10.

30 Colebatch JG, Gandevia SC. The distribution of muscular weakness in upper motor neuron lesions affecting the arm. Brain 1989;112:749-63.

31 Chollet F, DiPiero V, Wise RJS, et al. The functional anatomy of moto recovery after ischaemic stroke in man: a study with positron emission tomography. Ann Neurol (in press).

32 Wise RJS. Personal Communication. reserve in patients with carotid artery occlusion. Lancet 1984;i:310-14.

34 Powers WJ, Press GA, Grubb RL, Gado M, Raichle ME. The effect of haemodynamically significant carotid artery disease on the haemodynamic status of the cerebral circulation. Ann Int Med 1987;106:27-35.

35 Wise RJS, Bernardi S, Frackowiak RSI, Legg NJ, Jones T. Seria observations on the pathophysiology of acute stroke. Brain 1983;106: 197-222.

36 Hakim AM, Pokrupa RP, Villanueve J, et al. The effect of spontaneous reperfusion on metabolic function in early human cerebral infarcts. $A n n$ Neurol 1987;21:279-89.

37 Baron JC, Comar D, Bousser MG, et al. Etude tomographique, che l'homme du debit sanguin et de la consommation d'oxygene du cerveau pa inhalation continue d'oxygene-15. Rev Neurol 1978;134:545-56.

38 Baron JC, Bousser MG, Rey A, et al. Reversal of focal "misery-perfusion syndrome" by extra-intracranial artery bypass in haemodynamic cerebra ischaemia. Stroke 1981;12:454-9.

39 Gibbs JM, Wise RJS, Thomas DJ, Mansfield AO, Ross Russell R. Cerebral haemodynamic changes after extracranial-intracranial bypass surgery. Neurol Neurosurg Psychiatry 1987;50:140-50.

40 Powers WJ, Martin WRW, Herscovitch P, Raichle ME, Grubb RL. Extracranial-intracranial bypass surgery: haemodynamic and metabolic effects. Neurology 1984;34:1168-74.

41 Samson Y, Baron JC, Bousser MG, et al. Effects of extra-intracranial bypass on cerebral blood flow and oxygen metabolism in humans. Stroke 1986;16:609-14.

42 Powers WJ, Grubb RL, Tempel LW, Carpenter DA, Raichle ME. Cerebral haemodynamics and 2-year stroke risk. J Cereb Blood Flow Metabol 1989;9:S356.

43 Wolfson LI, Leenders KL, Brown LL, Jones T. Alterations of regional cerebral blood flow and oxygen metabolism in Parkinson's disease. Neurology 1985;35:1399-405.

44 De Volder AG, Francard J, Laterre C, et al. Decreased glucose utilisation in the striatum and frontal lobe in probable striatonigral degeneration. Ann Neurol 1989;26:236-47.

45 Hayden MR, Martin WRW, Stoessl AJ, et al. Positron emission tomography 
in the early diagnosis of Huntington's disease. Neurology 1986;36:888-94. 46 Brooks DJ, Frackowiak RS J. Functional imaging of movement disorders. In: Marsden CD, Fahn S, eds. Movement disorders 3 . Butterworths (in press). 47 Mazziotta JC, Phelps ME, Pahl JJ, et al. Reduced cerebral glucose metabolism in asymtomatic subjects at risk for Huntington's Disease. New Engl J Med 1987;316:357-62.

48 Brooks DJ, Ibanez V, Sawle GV, et al. Differing patterns of striatal ${ }^{18} \mathrm{~F}$-Dopa uptake in Parkinson's disease, multiple system atrophy, and progressive supranuclear palsy. Ann Neurol 1990;28:547-55.

49 Leenders KL, Palmer AJ, Quinn N, et al. Brain dopamine metabolism in patients with Parkinson's disease measured with positron emission tomography. J Neurol Neurosurg Psychiatry 1986;49:853-60.

50 Calne DB, Langston WJ, Martin WRW, et al. Positron emission tomography after MPTP: observations relating to the cause of Parkinson's disease. Nature 1985;317:246-8.

51 Brooks DJ, Ibanez V, Sawle GV, et al. PET studies on the integrity of Striatal Pre- and Post-synaptic dopaminergic systems in idiopathic Parkinson's disease, drug-induced, and atypical Parkinsonism. In: Ánoli A, ed. European conference on Parkinson's disease and extrapyramidal disorders, Rome, 1990. John Libbey (in press)

52 Rinne UK, Laihinen A, Rinne JO, et al. Positron Emission Tomography demonstrates dopamine $D_{2}$ receptor supersensitivity in the striatum of patients with early Parkinson's disease. Movement Disorders 1990;5:55-9.

53 Sawle GV, Brooks DJ, Ibanez V, Frackowiak RSJ. Striatal $D_{2}$ receptor density is inversely proportional to dopa uptake in untreated hemiParkinson's disease. J Neurol Neurosurg Psychiatry 1990;53:177.
54 Baron JC, Mazière B, Loc'h C, et al. Loss of striatal $\left[{ }^{76} \mathrm{Br}\right] \mathrm{Bromospiperone}$ binding sites demonstrated by positron emission tomography in progressive supranuclear palsy. J Cereb Blood Flow Metabol 1986;6:131-6.

55 Rosenthal G, Gilman S, Koeppe RA, et al. Motor dysfunction in olivo. pontocerebellar atrophy is related to cerebral metabolic rate

56 Dubinsky RM, Brown RT, Polinsky RJ, Di Chiro G, Hallett M. Regional brain glucose hypometabolism in multiple system atrophy. Neurology

57 Gilman S, Junck L, Gebarski SS, et al. Friedreich's ataxia: comparison of clinical, CT, and PET-FDG findings. Neurology 1990;40(Suppl 1):155.

58 Theodore WH, Brooks R, Margolin R, et al. Positron emission tomography in generalised seizures. Neurology 1985;35:684-90.

59 Engel J Jr, Kuhl DE, Phelps ME. Patterns of human local cerebral glucose metabolism during epileptic seizures. Science 1982;218:64-6.

60 Engel J Jr, Kuhl DE, Phelps ME, et al. Inter-ictal cerebral glucose metabolism in partial epilepsy and its relation to EEG changes. Ann Neurol 1982;12:510-17.

61 Abou-Khalil BW, Siegel GJ, Sackellares JC, et al. Positron emission tomography studies of cerebral glucose metabolism in chronic partial epilepsy. Ann Neurol 1987;22:480-6.

62 Engel J Jr, Brown EJ, Kuhl DE, et al. Pathological findings underlying focal temporal lobe hypometabolism in partial epilepsy. Ann Neurol 1982; $12 \cdot 518-28$.

63 Latack JT, Abou-Khalil BW, Siegel GJ, et al. Patients with partial seizures: evaluation by MRI, CT, and PET imaging. Radiology 1986;159:1951-63.

Neurological stamps

\section{Hippocrates 460-377 BC}

Hippocrates recognised diseases of the brain. He noted that the brain had two halves and was well supplied with blood vessels, some slender but two were stout. Hippocrates believed that these vessels contained air. Indeed, at that time, nerves were not distinguished from tendons or ligaments. The brain, however, was associated with intelligence, dreams, thoughts and epilepsy. It was assumed to have a cooling mechanism mediated by secretion of phlegm or, as it was also called, pituita.

At the time of Hippocrates it was known that a head wound could be followed by paralysis of the opposite side of the body, whilst spinal cord compression could cause anaesthesia and weakness as well as urinary and faecal retention. Hippocrates described peuperal hemiplegia, aphasia, migraine, irregular respiration from cerebral disease, febrile delirium, mania and melancholia. He also knew of the neurological sequelae of alcoholism and noted that "Unaccustomed attacks of anaesthesia and numbness are impending signs of apoplexy".

Hippocrates has been featured on stamps on a number of occasions. The illustrations here commemorate the reincorporation of the Dodecanese Islands into Greece. On the right is the plane tree at the centre of the town of Cos in the shade of which Hippocrates is reputed to have taught his pupils.

These stamps, the first in a series to be published in this journal, can be found in the catalogues of Stanley Gibbons (670 and 817) or Scott (514 and 657).

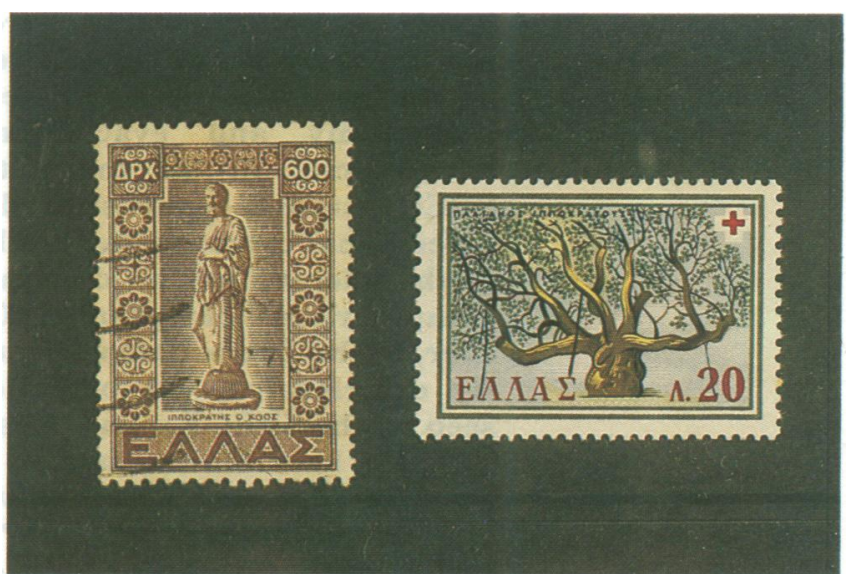

